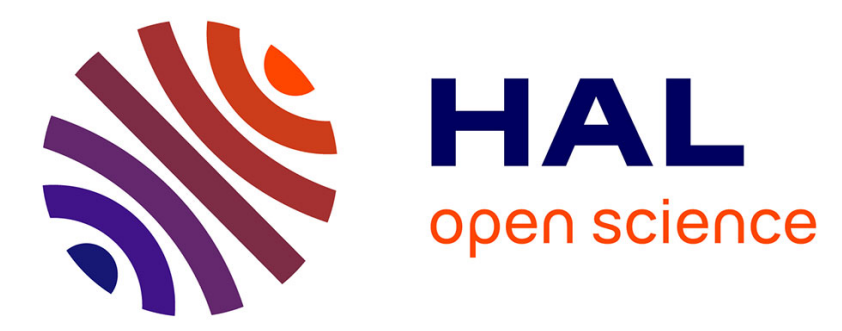

\title{
A Bibliometric Analysis and Research Agenda on Smart Cities
}

\author{
Fosso Wamba Fosso Samuel, Maciel M. Queiroz
}

\section{To cite this version:}

Fosso Wamba Fosso Samuel, Maciel M. Queiroz. A Bibliometric Analysis and Research Agenda on Smart Cities. International Working Conference on Transfer and Diffusion of IT (TDIT), Jun 2019, Accra, Ghana. pp.325-335, 10.1007/978-3-030-20671-0_22 . hal-02294691

\section{HAL Id: hal-02294691 \\ https://hal.inria.fr/hal-02294691}

Submitted on 23 Sep 2019

HAL is a multi-disciplinary open access archive for the deposit and dissemination of scientific research documents, whether they are published or not. The documents may come from teaching and research institutions in France or abroad, or from public or private research centers.
L'archive ouverte pluridisciplinaire HAL, est destinée au dépôt et à la diffusion de documents scientifiques de niveau recherche, publiés ou non, émanant des établissements d'enseignement et de recherche français ou étrangers, des laboratoires publics ou privés.

\section{(c)(1)}

Distributed under a Creative Commons Attribution| 4.0 International License 


\title{
A Bibliometric Analysis and Research Agenda on Smart Cities
}

\author{
Samuel Fosso Wamba ${ }^{1[0000-0002-1073-058 X]}$ and Maciel M. Queiroz ${ }^{20000-0002-6025-9191]}$ \\ ${ }^{1}$ Toulouse Business School (TBS), Toulouse 31068, France \\ ${ }^{2}$ Paulista University (UNIP), São Paulo 04026002, Brazil \\ s.fosso-wamba@tbs-education.fr, maciel.m.queiroz@gmail.com
}

\begin{abstract}
Smart cities or intelligent cities have been gaining visibility and importance in recent years; not only in academia but also in the agendas of governments. Smart cities represent an important and disruptive interplay of cities' infrastructure, technologies, and people. Advancements in information and communication technology (ICT) have been supported by the development of cutting-edge technologies that involve the behaviors and experiences of city dwellers. In this context, smart cities have changed drastically in the last years. However, due to the rapid advancement of this multidisciplinary field, scholars and practitioners have encountered some difficulties in catalysing the latest advances as well as identifying a consistent and robust research agenda on this hot topic. In order to understand the evolution of this field, this study used bibliometric and network analysis; and identified top authors and articles. Also, we provided research directions based on cluster classification. Lastly, this study offers theoretical and managerial contributions.
\end{abstract}

Keywords: Smart Cities, Intelligent Cities, Research Agenda.

\section{Introduction}

Nowadays, $55 \%$ of people in the world live in urban areas [1] and according to projected estimates, approximately $68 \%$ of the world's population will live in cities (urban areas) by 2050 . This increase in population growth is already bringing unprecedented consequences to the cities, its people and their quality of life; provoking climate change. Due to this landscape and the recent advances in information and communications technologies (ICT), cities need to become smarter in terms of resource consumption.

Due to the exponential growth of data [2]-[4], the advances of smartphone applications, smart products (e.g., smart TVs, smart-watch, smart clothes, among others), smart semaphore, especially with the advent of internet of things (IoT) and sensors applications, the experiences of city dwellers have changed drastically in the last years. In addition, with the use of GPS in activities that depend on vehicles, cities can accumulate important data on the behaviour of citizens in order to develop government policies to address resource usage and the well-being of the population.

In this context, a smart city can be defined as "urban areas that exploit operational data such as; that arising from traffic congestion, power consumption statistics, and 
public safety events, to optimize the operation of city services" [5]. In recent years, various scholars have devoted considerable efforts to provide information about the evolution of smart cities concepts [6]-[8]. In this vein, a smart city occurs when its traditional infrastructure is merged with ICT in an integrated and coordinated manner [9]. Recent studies have shown two cutting-edge technologies that have the potential to leverage smart cities; big data [10], [11], and the internet of things (IoT) [12], [13]. In addition, smart cities have the potential to leverage the quality of life as well as the performance of the firms that use their infrastructure [14].

Moreover, the smart cities can be visualized by six main dimensions (smart economy, smart people, smart governance, smart mobility, smart environment, and smart living) [15], [16]. Thus, recent studies have been highlighting the importance of smart cities in various contexts [17]-[21]. However, there are various barriers associated with their development [22].

Despite these significant and important innovations in the smart city field, there exists a gap in the literature regarding the bibliometric perspective in organizing and analysing the advances in this research stream; same as in the current trends. In order to outperform this gap, this study aims to 1) identify the literature on smart cities taking into consideration the period from 2000 to 2018; 2) Give insights on the more influential studies using a bibliometric and network analysis approach; 3) Provide research directions to scholars and insights to practitioners and managers.

By employing a bibliometric and network analysis approach, we identified 1226 articles, which were filtered and analysed in order to understand the dynamics of this field. Therefore, our study offers an essential contribution to theory and practice by identifying the most influential articles and suggesting new research. The next section of this paper presents the smart cities brief concept. In sequence, the methodology is highlighted, followed by results analysis. Next, the discussion and research agenda is

provided. Finally, the main conclusions are synthesized.

\section{Smart Cities: Brief Concepts}

A smart city (or intelligent city) is defined [7] as "when investments in human and social capital, traditional (transport) and modern (ICT) communication infrastructure fuel sustainable economic growth and a high quality of life, with a wise management of natural resources; through participatory governance". There are several definitions of smart cities in existing literature (see [6]). However, based on majority dynamics, there is an interplay between ICT, people, government, and resource consumption.

Recent studies on smart cities have contributed significantly by integrating and expanding concepts with frameworks. For instance, [23] presented an approach in which smart cities integrate energy (sustainability and optimization), mobility (movement), community (participation and communication), environment (enhancement), and economy (dynamism and innovation). Another interesting framework was provided by [12], whereby integrating smart cities approach with the internet of things (IoT), provided an 
urban information system that connects intelligent transportation, video monitoring, health monitoring, and environmental monitoring, among others.

Following the frameworks' perspective, [24] proposed an engaging framework called the SMART model. The purpose of this model was to provide insights into smart cities' implementation, integrating strategy levels and strategic steps, as well as dimensions, and focus. Finally, [25] provided a good literature review on the smart city field and proposed a framework on the smart cities schools of thought.

\section{Method}

This study follows a bibliometric approach (Caviggioli \& Ughetto, 2019; Mishra, Gunasekaran, Papadopoulos, \& Childe, 2018) to identify, collect, organize, and analyse articles about smart cities. Firstly, in the keywords definition, we used the following combination: smart cit* OR intelligent cit* in the titles of the articles published in English between 2000 and 2018, in the Web of Science (WOS) database. WOS is one of the largest databases worldwide [28] and has been used frequently in studies reporting literature reviews [29]. The search resulted in 1,226 articles. We analyzed the articles by employing an excel spreadsheet [30] and VOSviewer to network analysis [27].

\section{$4 \quad$ Results}

\subsection{Articles Published by Year and Top Twenty Journals}

As the initial analysis, Fig. 1 highlights the number of articles published by year during the period 2000-2018. As can be seen, between 2000 and 2009, the maximum number of papers published in a year was 4 . As of 2010, the number of articles has seen exponential growth, reaching 460 articles in 2018. Moreover, Table 1 shows the top twenty journals based on the number of publications. The journal with most articles published was Sensors with 60, followed by IEEE ACCESS with 46 articles. It is important to point out that both journals are open access format. 


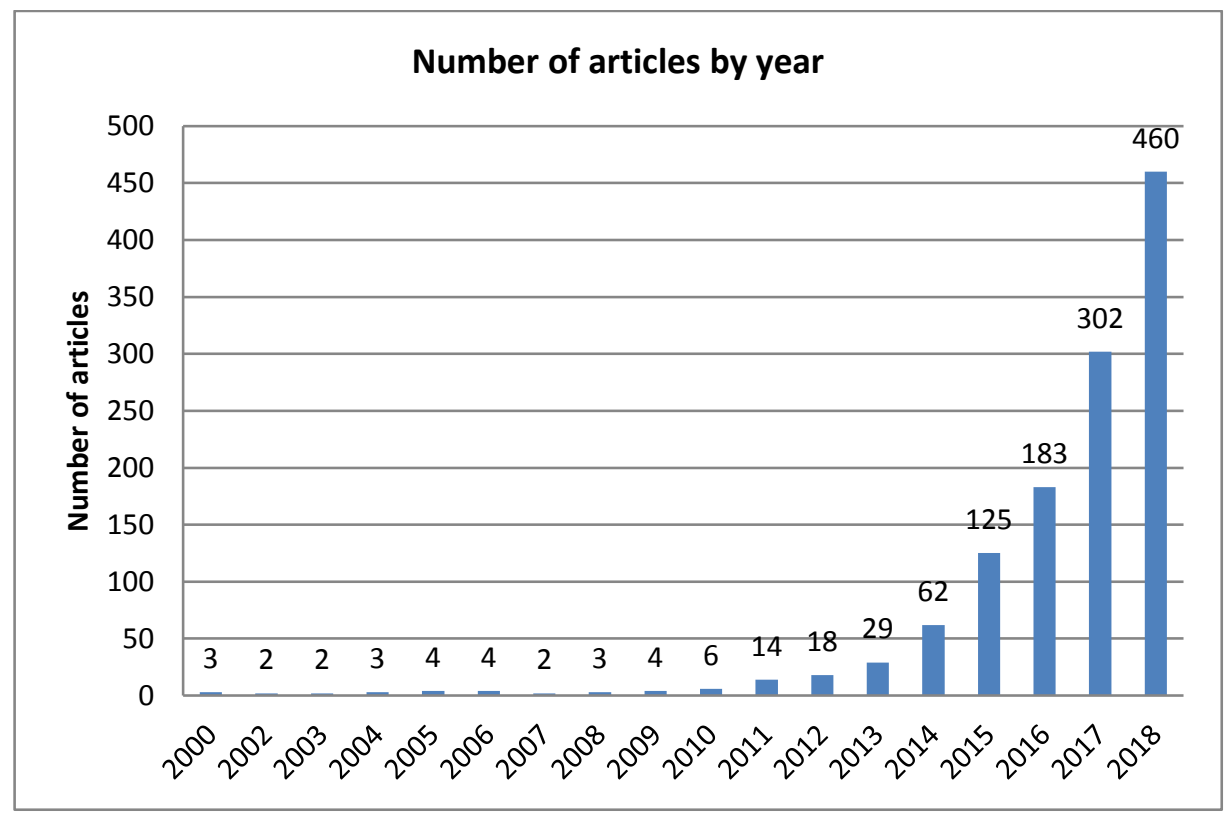

Fig. 1. Distribution of articles published between 2000-2018

Table 1. Table captions should be placed above the tables.

\begin{tabular}{lcc}
\hline Journal & Number of articles & Rank \\
\hline Sensors & 60 & 1 \\
IEEE Access & 46 & 2 \\
IEEE Communications Magazine & 45 & 3 \\
Sustainability & 36 & 4 \\
Future Generation Computer Systems the In- & & \\
ternational Journal of eScience & 35 & 5 \\
Sustainable Cities and Society & 29 & 6 \\
Cities & 25 & 7 \\
IEEE Internet of Things Journal & 22 & 8 \\
Journal of Urban Technology & 19 & 9 \\
International Journal of Distributed Sensor & & \\
Networks & 15 & 10 \\
IEEE Transactions on Industrial Informatics & 14 & 11 \\
Wireless Communications Mobile Computing & 12 & 12 \\
Wireless Personal Communications & 12 & 13 \\
IEEE Internet Computing & 11 & 14 \\
Personal and Ubiquitous Computing & 11 & 15 \\
Techne Journal of Technology for Architec- & & \\
ture and Environment & 11 & 16 \\
Computer & 10 & 17 \\
Government Information Quarterly & 10 & 18
\end{tabular}


IEEE Transactions on Intelligent Transpor-

$\begin{array}{lll}\text { tation Systems } & 10 & 19\end{array}$

$\begin{array}{lll}\text { Journal of Cleaner Production } & 10 & 20\end{array}$

\subsection{Authors and Papers Influence}

To analyse the influence of the authors, the data from WOS was extracted and analysed using VOSviewer. Table 2 presents the top ten contributing authors, the number of articles published, and the total citations. The author that dominated the list was Zanella with 1104 citations, followed by Zorzi, and Vangelista, with 1102 and 1098 citations, respectively. However, it can be seen that Bui, and Castellani with 983 citations each, have high influence because all their citations are concentrated in only one article. In addition, Table 3 highlights the most influential articles. In this sense, [13] Zanella, Bui, Castellani, Vangelista, \& Zorzi (2014) was the most cited article, with 983 citations, followed by [7] Caragliu et al. (2011) with 551 citations.

Table 2. Top ten authors based on the number of citations.

\begin{tabular}{llll}
\hline \multicolumn{1}{c}{ Authors } & Articles & Citations & Rank \\
\hline Zanella, A. & 4 & 1104 & 1 \\
Zorzi, M. & 3 & 1102 & 2 \\
Vangelista, L. & 2 & 1098 & 3 \\
Bui, N. & 1 & 983 & 4 \\
Castellani, A. & 1 & 983 & 5 \\
Nijkamp, P. & 6 & 642 & 6 \\
Caragliu, A. & 3 & 557 & 7 \\
Del bo, C. & 2 & 551 & 8 \\
De Marco, A. & 3 & 374 & 9 \\
Scorrano, F. & 1 & 369 & 10 \\
\hline
\end{tabular}

Note: Co-authored papers were counted. For example, Bui and Castellani are authors of the same article. The number of citations considered up to February 25, 2019.

Table 3. Top ten articles based on citation.

\begin{tabular}{lll}
\hline \multicolumn{1}{c}{ Article } & Citations & Rank \\
\hline$[13]$ & 983 & 1 \\
{$[7]$} & 551 & 2 \\
{$[8]$} & 369 & 3 \\
{$[9]$} & 356 & 4 \\
{$[33]$} & 332 & 5
\end{tabular}




\begin{tabular}{lll}
{$[12]$} & 308 & 6 \\
{$[34]$} & 265 & 7 \\
{$[6]$} & 237 & 8 \\
{$[35]$} & 193 & 9 \\
{$[5]$} & 192 & 10 \\
\hline
\end{tabular}

\subsection{Publication by Country and Research Areas}

Table 4 shows the top twenty countries contributing papers. China is on the top of the list with 195 publications, followed by Italy, USA, and Spain, with 169, 164, and 144 articles, respectively. It is clear that the countries from Europe and Asia dominate the list. North America, represented by USA and Canada reached meaningful participation. In addition, Brazil was the only Latin American country represented. Moreover, Table 5 presents the most influential areas of research interested in smart cities.

Table 4. Top twenty countries contributing papers.

\begin{tabular}{lcclcc}
\hline \multicolumn{1}{c}{ Countries/Regions } & $\begin{array}{l}\text { Number of pa- } \\
\text { pers }\end{array}$ & Rank & Countries/Regions & $\begin{array}{l}\text { Number of } \\
\text { papers }\end{array}$ & Rank \\
\hline Peoples R. of China & 195 & 1 & Netherlands & 43 & 11 \\
Italy & 169 & 2 & France & 42 & 12 \\
USA & 164 & 3 & Germany & 42 & 13 \\
Spain & 144 & 4 & Saudi Arabia & 38 & 14 \\
England & 127 & 5 & Brazil & 32 & 15 \\
South Korea & 71 & 6 & Pakistan & 29 & 16 \\
India & 55 & 7 & Japan & 28 & 17 \\
Australia & 51 & 8 & Ireland & 26 & 18 \\
Canada & 48 & 9 & Finland & 24 & 19 \\
Greece & 44 & 10 & Portugal & 24 & 20 \\
\hline
\end{tabular}

Table 5. Top ten research areas.

\begin{tabular}{|c|c|c|}
\hline Research Areas & $\begin{array}{l}\text { Number of ar- } \\
\text { ticles }\end{array}$ & Rank \\
\hline Computer science & 409 & 1 \\
\hline Engineering & 316 & 2 \\
\hline Telecommunications & 258 & 3 \\
\hline Business economics & 96 & 4 \\
\hline Environmental sciences ecology & 95 & 5 \\
\hline
\end{tabular}




\begin{tabular}{lll} 
Science technology and other topics & 95 & 6 \\
Urban studies & 87 & 7 \\
Chemistry & 74 & 8 \\
Instruments instrumentation & 72 & 9 \\
Electrochemistry & 63 & 10 \\
\hline
\end{tabular}

\subsection{Network Analysis Based on Co-Citation}

Recent studies have highlighted the importance of network analysis (Mishra, Gunasekaran, Papadopoulos, \& Dubey, 2018; Mishra et al., 2018) in the understanding of co-citation. Thus, co-citation analysis is commonly used to gain a better understanding of the relationship between the authors; but, it can also cover other relationships including keywords and journals (Mishra et al., 2018). In this vein, our co-citation took into account the cited articles as the unit of analysis, employing VOSviewer. Therefore, we are interested in the intellectual relationships in the field (Mishra et al., 2018). Of 27251 identified authors, our threshold was 30 citations of an article; representing the minimum number of citations of a cited reference. This criterion reappeared in 40 articles, distributed in 3 clusters. For each of the 40 cited references, the total strength of the cocitation links with other cited references was calculated (Figure 2). Besides, Table 6 shows the top 5 publications by each cluster. 


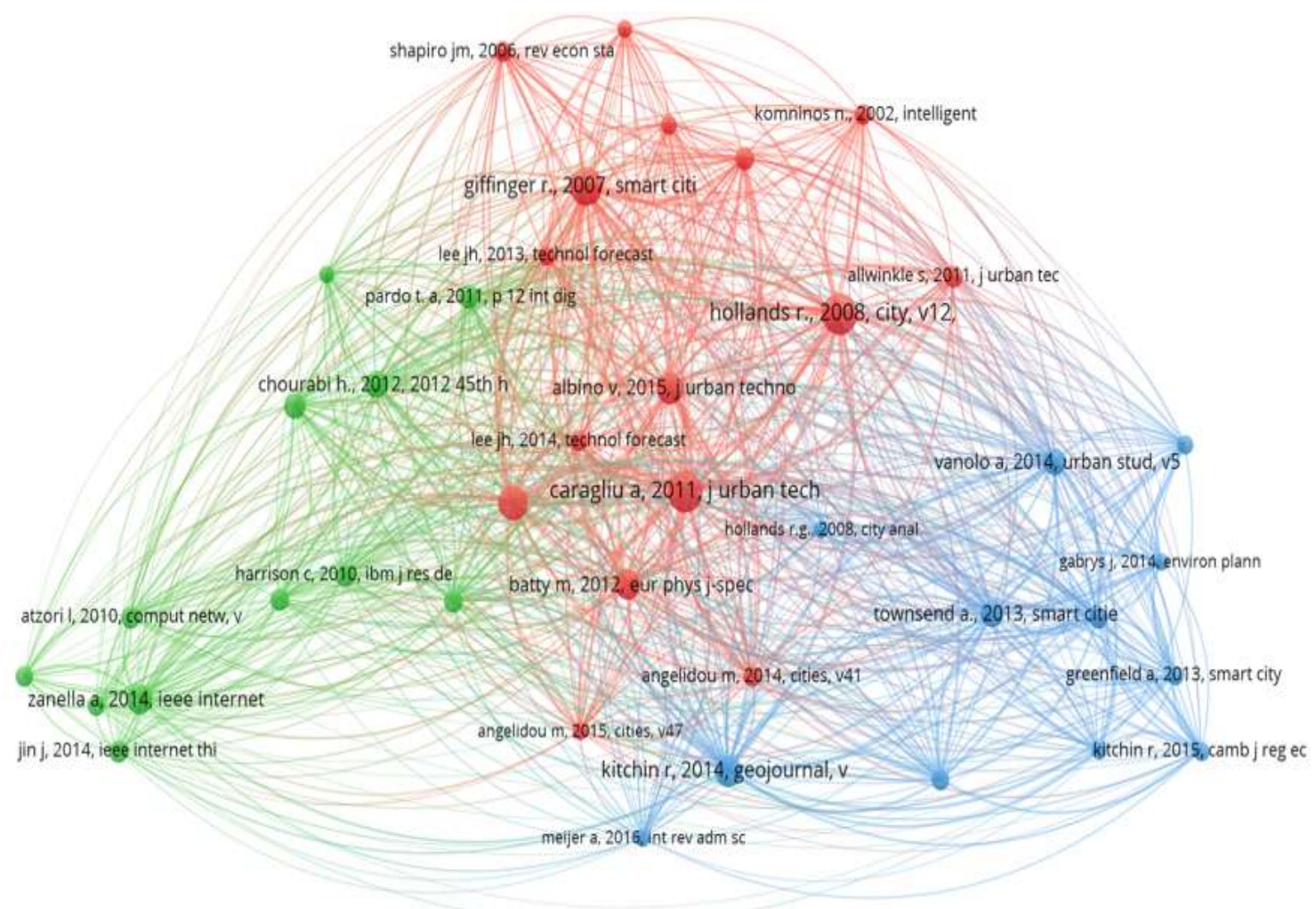

Fig. 2. Clusters based on the co-citation

Table 6. Articles organized in a cluster based on top five studies-weight citations.

\begin{tabular}{|c|c|c|c|c|}
\hline & Cluster & Weight (Links) & $\begin{array}{l}\text { Weight (Total } \\
\text { link strength) }\end{array}$ & $\begin{array}{r}\text { Weight } \\
\text { (Citations) } \\
\end{array}$ \\
\hline [7] & 1 & 39 & 849 & 151 \\
\hline [37] & 1 & 38 & 750 & 150 \\
\hline [38] & 1 & 39 & 709 & 127 \\
\hline [8] & 1 & 39 & 618 & 107 \\
\hline [6] & 1 & 39 & 521 & 88 \\
\hline [13] & 2 & 37 & 210 & 83 \\
\hline [39] & 2 & 39 & 341 & 70 \\
\hline [40] & 2 & 38 & 271 & 60 \\
\hline [41] & 2 & 39 & 264 & 53 \\
\hline [42] & 2 & 35 & 174 & 46 \\
\hline [10] & 3 & 39 & 544 & 90 \\
\hline [43] & 3 & 38 & 492 & 68 \\
\hline [11] & 3 & 38 & 441 & 66 \\
\hline
\end{tabular}




\begin{tabular}{lllll}
{$[44]$} & 3 & 37 & 368 & 49 \\
{$[45]$} & 3 & 38 & 293 & 38 \\
\hline
\end{tabular}

\section{Discussion and Research Agenda}

This study brings contribution from both, theoretical and managerial fields. In the lens of theoretical contribution, our research covered a period from 2000-2018 in smart cities publication; firstly, by employing a bibliometric strategy. We can subdivide our analysis into two periods 2000-2009, in which the maximum number of papers published by year was 4, and 2010-2018, in which each year noted a substantial growth, achieving 460 articles in 2018.

Also, we identified the top 20 journals based on the number of articles published, and we discovered that the first two were open access journals. The most influential authors were also identified in the process. Regarding the countries contributing papers, China topped the list. Also, the top research areas based on the number of articles, were computer science, engineering, and telecommunications, respectively. Finally, based on the study of [27], we proposed a cluster classification (Table 7), identifying current research and providing insights for future research. Table 7 is an important contribution to theory; it can guide scholars in conducting future studies.

Table 7. Cluster classification and research agenda.

\begin{tabular}{cll}
\hline Cluster & \multicolumn{1}{c}{ Current research } & \multicolumn{1}{c}{ Suggestions for future research } \\
\hline 1 & $\begin{array}{l}\text { Concepts, definitions, and under- } \\
\text { standing of smart cities }\end{array}$ & $\begin{array}{l}\text { Models and theories to advance the smart } \\
\text { cities understanding taking into account the } \\
\text { countries' particularities }\end{array}$ \\
2 & $\begin{array}{l}\text { Frameworks to describe the inte- } \\
\text { gration of smart cities with technol- } \\
\text { ogies }\end{array}$ & $\begin{array}{l}\text { Frameworks to understand the effect of cut- } \\
\text { artificial intelligence) to smart cities devel- } \\
\text { opment } \\
\text { Big data analytics applied to optimize the } \\
\text { integration of people, government policies } \\
\text { and firms }\end{array}$ \\
\hline
\end{tabular}

Thus, the proposed cluster classification and research agenda can generate insights for scholars and practitioners interested in gaining a deeper understanding, as well as contribute to the advancement of the field. For instance, cluster 1, has its current studies focused basically on the concepts. Also, we identified the necessity of advancing the understanding of smart cities' definitions and concepts in different countries. Example of research questions: i) Are the six dimensions of the smart cities valid for any country? ii) Are there differences between developing and developed economies regarding 
the smart cities understanding? iii) What is the awareness level of smart cities by citizens from different countries? Considering cluster 2 that is focused on frameworks and the integration with technologies, some suggestions to advance the field could be related to frameworks that can integrate different technologies to support the firm's new operations business models. Finally, in cluster 3, there exists an interesting interplay between big data and smart city governance. Future studies could explore more in-depth models associated to citizen behaviour data, in order to support decision-makers and governance policies for the well-being of people and the promotion of the use of resources in an optimized way by the organizations.

From the managerial perspective, our study brings opportunities to managers and practitioners, as well as to government policy makers. For example, based on the top 20 countries contributing articles, we identified a gap in the unavailability of articles from emerging economies from Latin America and Africa. The lack in participation could be associated to a gap in smart cities projects and implementation in these countries. In addition, the proposed cluster classification could be a starting point for managers and practitioners to improve their awareness of smart cities, and consequently, generate insights to enable them integrate and develop projects for their businesses based on the smart cities technologies.

\section{Conclusions}

Based on the bibliometric approach and network analysis, this study covered a period from 2010-2018 in smart cities articles. Our study provided significant insights for scholars and practitioners interested in gaining more insights into the smart cities past and trends. In terms of the main limitations, we highlight the following: i) we considered the keywords only in the title of the articles. Future studies can consider the search terms in the abstract, as well as in the other articles' section; ii) we focused on the WOS database. Future studies can consider other databases such as Scopus; iii) we developed the cluster using VOSviewer, other software can bring different results. Despite these limitations, our study provides useful insights for scholars and practitioners interested in smart cities.

\section{References}

[1] U. N. UN, " $68 \%$ of the world population projected to live in urban areas by 2050 , says UN," $2018 . \quad$ [Online]. Available: https://www.un.org/development/desa/en/news/population/2018-revision-of-worldurbanization-prospects.html.

[2] J. Manyika et al., "Big data: The next frontier for innovation, competition, and productivity," McKinsey Global Institute, 2011. [Online]. Available: https://www.mckinsey.com/business-functions/digital-mckinsey/ our-insights/big-data-the-next-frontierfor-innovation.

[3] M. M. Queiroz and R. Telles, "Big data analytics in supply chain and logistics: an empirical approach," Int. J. Logist. Manag., vol. 29, no. 2, pp. 767-783, 2018.

[4] S. F. Wamba, S. Akter, A. Edwards, G. Chopin, and D. Gnanzou, "How 'big data' can 
make big impact: Findings from a systematic review and a longitudinal case study," Int. J. Prod. Econ., vol. 165, pp. 234-246, 2015.

[5] C. Harrison et al., "Foundations for Smarter Cities," IBM J. Res. Dev., vol. 54, no. 4, pp. 1-16, Jul. 2010.

[6] V. Albino, U. Berardi, and R. M. Dangelico, "Smart cities: Definitions, dimensions, performance, and initiatives," J. Urban Technol., vol. 22, no. 1, pp. 1-19, 2015.

[7] A. Caragliu, C. Del Bo, and P. Nijkamp, "Smart Cities in Europe," J. Urban Technol., vol. 18, no. 2, pp. 65-82, Apr. 2011.

[8] P. Neirotti, A. De Marco, A. C. Cagliano, G. Mangano, and F. Scorrano, "Current trends in Smart City initiatives: Some stylised facts," Cities, vol. 38, pp. 25-36, Jun. 2014.

[9] M. Batty et al., "Smart cities of the future," Eur. Phys. J. Spec. Top., vol. 214, no. 1, pp. 481-518, Nov. 2012.

[10] R. Kitchin, "The real-time city? Big data and smart urbanism," GeoJournal, vol. 79, no. 1, pp. 1-14, Feb. 2014.

[11] A. M. Townsend, Smart Cities: Big Data, Civic Hackers, and the Quest for a New Utopia. 2013.

[12] J. Jin, J. Gubbi, S. Marusic, and M. Palaniswami, "An Information Framework for Creating a Smart City Through Internet of Things," IEEE Internet Things J., vol. 1, no. 2, pp. 112-121, Apr. 2014.

[13] A. Zanella, N. Bui, A. Castellani, L. Vangelista, and M. Zorzi, "Internet of Things for Smart Cities," IEEE Internet Things J., vol. 1, no. 1, pp. 22-32, Feb. 2014.

[14] E. Ismagilova, L. Hughes, Y. K. Dwivedi, and K. R. Raman, "Smart cities: Advances in research-An information systems perspective," Int. J. Inf. Manage., vol. 47, pp. 88100, Aug. 2019.

[15] P. Lombardi, S. Giordano, H. Farouh, and W. Yousef, "Modelling the smart city performance,” Innov. Eur. J. Soc. Sci. Res., vol. 25, no. 2, pp. 137-149, Jun. 2012.

[16] V. Albino, U. Berardi, and R. M. Dangelico, "Smart Cities: Definitions, Dimensions, Performance, and Initiatives," J. Urban Technol., vol. 22, no. 1, pp. 3-21, Jan. 2015.

[17] K. Axelsson and M. Granath, "Stakeholders' stake and relation to smartness in smart city development: Insights from a Swedish city planning project," Gov. Inf. Q., vol. 35, no. 4, pp. 693-702, Oct. 2018.

[18] Á. Palomo-Navarro and J. Navío-Marco, "Smart city networks' governance: The Spanish smart city network case study," Telecomm. Policy, vol. 42, no. 10, pp. 872-880, Nov. 2018

[19] H. Haarstad and M. W. Wathne, "Are smart city projects catalyzing urban energy sustainability?," Energy Policy, vol. 129, pp. 918-925, Jun. 2019.

[20] D. van den Buuse and A. Kolk, "An exploration of smart city approaches by international ICT firms," Technol. Forecast. Soc. Change, vol. 142, pp. 220-234, May 2019.

[21] A. Caragliu and C. F. Del Bo, "Smart innovative cities: The impact of Smart City policies on urban innovation," Technol. Forecast. Soc. Change, vol. 142, pp. 373-383, May 2019.

[22] N. P. Rana, S. Luthra, S. K. Mangla, R. Islam, S. Roderick, and Y. K. Dwivedi, "Barriers to the Development of Smart Cities in Indian Context," Inf. Syst. Front., Jul. 2018.

[23] B. Mattoni, F. Gugliermetti, and F. Bisegna, "A multilevel method to assess and design the renovation and integration of Smart Cities," Sustain. Cities Soc., vol. 15, pp. 105119, 2015.

[24] S. Ben Letaifa, "How to strategize smart cities: Revealing the SMART model," J. Bus. Res., vol. 68, no. 7, pp. 1414-1419, 2015.

[25] R. K. R. Kummitha and N. Crutzen, "How do we understand smart cities? An evolutionary perspective," Cities, vol. 67, no. July 2016, pp. 43-52, 2017.

[26] F. Caviggioli and E. Ughetto, "A bibliometric analysis of the research dealing with the impact of additive manufacturing on industry, business and society," Int. J. Prod. Econ., 
vol. 208, pp. 254-268, Feb. 2019.

[27] D. Mishra, A. Gunasekaran, T. Papadopoulos, and S. J. Childe, "Big Data and supply chain management: a review and bibliometric analysis," Ann. Oper. Res., vol. 270, no. 1-2, pp. 313-336, 2018.

[28] Clarivate Analytics, "Web of Science," 2019.

[29] Y. Liao, F. Deschamps, E. de F. R. Loures, and L. F. P. Ramos, "Past, present and future of Industry 4.0 - a systematic literature review and research agenda proposal," Int. J. Prod. Res., vol. 55, no. 12, pp. 3609-3629, 2017.

[30] H. Blažun Vošner, S. Bobek, S. Sternad Zabukovšek, and P. Kokol, "Openness and information technology: a bibliometric analysis of literature production," Kybernetes, vol. 46, no. 5, pp. 750-766, May 2017.

[31] A. Zanella, N. Bui, A. Castellani, L. Vangelista, and M. Zorzi, "Internet of things for smart cities," IEEE Internet Things J., vol. 1, no. 1, pp. 22-32, 2014.

[32] A. Caragliu, C. del Bo, and P. Nijkamp, "Smart cities in Europe," J. Urban Technol., vol. 18, no. 2, pp. 65-82, 2011.

[33] J. M. Shapiro, "Smart Cities: Quality of Life, Productivity, and the Growth Effects of Human Capital," Rev. Econ. Stat., vol. 88, no. 2, pp. 324-335, May 2006.

[34] C. Perera, A. Zaslavsky, P. Christen, and D. Georgakopoulos, "Sensing as a service model for smart cities supported by Internet of Things," Trans. Emerg. Telecommun. Technol., vol. 25, no. 1, pp. 81-93, Jan. 2014.

[35] F. Axisa, P. M. Schmitt, C. Gehin, G. Delhomme, E. McAdams, and A. Dittmar, "Flexible Technologies and Smart Clothing for Citizen Medicine, Home Healthcare, and Disease Prevention," IEEE Trans. Inf. Technol. Biomed., vol. 9, no. 3, pp. 325-336, Sep. 2005.

[36] D. Mishra, A. Gunasekaran, T. Papadopoulos, and R. Dubey, Supply chain performance measures and metrics: a bibliometric study, vol. 25, no. 3. 2018.

[37] R. G. Hollands, "Will the real smart city please stand up?," City, vol. 12, no. 3, pp. 303320, Dec. 2008.

[38] E. Giffinger, R., Fertner, C., Kramar, H., Kalasek, R., Pichler-Milanovic, N., Meijers, "Smart cities - Ranking of European medium-sized cities," Vienna, 2007.

[39] H. Chourabi et al., "Understanding Smart Cities: An Integrative Framework," in 2012 45th Hawaii International Conference on System Sciences, 2012, pp. 2289-2297.

[40] H. Schaffers, N. Komninos, M. Pallot, B. Trousse, M. Nilsson, and A. Oliveira, "Smart Cities and the Future Internet: Towards Cooperation Frameworks for Open Innovation," 2011, pp. 431-446.

[41] T. Nam and T. A. Pardo, "Conceptualizing smart city with dimensions of technology, people, and institutions," in Proceedings of the 12th Annual International Digital Government Research Conference on Digital Government Innovation in Challenging Times - dg.o '11, 2011, p. 282.

[42] L. Atzori, A. Iera, and G. Morabito, "The Internet of Things: A survey," Comput. Networks, vol. 54 , no. 15 , pp. 2787-2805, Oct. 2010.

[43] A. Vanolo, "Smartmentality: The Smart City as Disciplinary Strategy," Urban Stud., vol. 51, no. 5, pp. 883-898, Apr. 2014.

[44] O. Söderström, T. Paasche, and F. Klauser, "Smart cities as corporate storytelling," City, vol. 18, no. 3, pp. 307-320, May 2014

[45] R. G. Hollands, "Critical interventions into the corporate smart city," Cambridge J. Reg. Econ. Soc., vol. 8, no. 1, pp. 61-77, Mar. 2015. 